\title{
Unexplained absence of an ovary and uterine tube
}

\author{
L. A. W. SirisEnA* \\ M.B., M.S., M.R.C.O.G. \\ Department of Obstetrics and Gynaecology, Hillingdon Hospital, Uxbridge, Middlesex.
}

\begin{abstract}
Summary
A case is reported of an incidental laparotomy finding of absence of left ovary and ipsilateral distal Fallopian tube. This is the fourth case to be reported in the English language literature. The three previous cases are reviewed and the probable aetiology discussed.

\section{Introduction}

Torsion of normal adnexae can happen in childhood and is an established surgical emergency. In the absence of early intervention, the result is adnexal infarction. Adnexal torsion seen in adult life is usually associated with some abnormality such as ovarian cyst. In fetal life, normal adnexae or adnexal tumours may undergo torsion and infarction, their discovery being incidental, some time after birth.
\end{abstract}

\section{Case report}

A 19-year-old Caucasian girl was admitted with a history of right-sided abdominal pain of 2 weeks' duration. There was no nausea, vomiting or fever. Her menarche had occurred at 13 years, with regular normal periods thereafter. She had had no previous abdominal operations.

A right-sided ovarian swelling was diagnosed and the patient was prepared for exploratory laparotomy on the following day. Laparotomy findings were as follows: uterus normal in size and shape and displaced to the left ; right ovary enlarged $(12 \times 7 \mathrm{~cm})$, mostly cystic but containing small hard solid areas, with the Fallopian tube elongated and stretched over the ovarian swelling; the pedicle not twisted; left ovary absent; left Fallopian tube also absent except for a length of $2 \mathrm{~cm}$ from its cornual end; round ligament on each side normal; thin fibrous band stretched from the left cornu of the uterus to the left lateral pelvic wall; filmy adhesions on the posterior aspect of the left broad ligament; left ovarian fossa explored but no trace of the missing ovary; left ureter visualized in the pelvis and a healthy appendix in the right iliac fossa.

Right ovarian cystectomy was performed and the specimen removed was a dermoid cyst.

Detailed inquiry during the postoperative phase, which evolved uneventfully, did not reveal any

\footnotetext{
* Present address: Department of Gynaecological Oncology, Queen Elizabeth Hospital, Gateshead NE9 6SX.
}

episodes of severe acute abdominal pain during childhood. An intravenous pyelogram showed a normal renal tract.

She continues to menstruate regularly, indicating normal ovarian function.

\section{Discussion}

Unilateral absence of an adnexa in the absence of previous surgery results either from unilateral failure of development of the urogenital ridge or from adnexal torsion with infarction. In the present case, a developmental anomaly seems unlikely she had a normal uterus, a right uterine appendage and also a normal renal tract. Further, there were no obvious Müllerian duct abnormalities. Thus previous torsion with consequent infarction becomes the most likely explanation. The fibrous band stretching from the left uterine cornu to the left lateral pelvic wall and adhesions at the back of the left broad ligament further substantiate this.

The previously reported cases are summarized in Table 1.

Authors of the first two cases came to the conclusion that 'asymptomatic torsion and infarction of a normal adnexa' had occurred some time earlier in life. In the third case the aetiology was not discussed.

Torsion of a normal adnexa usually occurs in childhood and is a well documented surgical emergency. At least forty-five cases occurring in children under 13 years of age have been reported in the literature (James, Barber and Graber, 1970; Grosfeld, 1969), and in every case the acute abdominal condition led to surgical exploration. Thus adnexal torsion and infarction occurring after birth is necessarily associated with acute symptoms and there cannot be such an entity as 'asymptomatic' torsion and infarction, as assumed by the previous authors. In all these cases there lies a possibility although it is unlikely - that infarction did occur during childhood and that the associated severe acute pain was so transient that it was overlooked, or that it was attributed to some other cause, as is sometimes the case with abdominal pain in infancy and childhood.

In these rare cases of incidental discovery of infarcted ovary and uterine tube, the more likely 
TABLE 1. Summary of cases of absence of adnexa recorded in the literature

\begin{tabular}{lcccc}
\hline \multicolumn{1}{c}{ Source } & $\begin{array}{c}\text { Age of patient } \\
\text { (years) }\end{array}$ & $\begin{array}{c}\text { Side } \\
\text { involved }\end{array}$ & $\begin{array}{c}\text { Mode of } \\
\text { diagnosis }\end{array}$ & $\begin{array}{c}\text { Indication } \\
\text { for procedure }\end{array}$ \\
\hline $\begin{array}{l}\text { Sebastian, Baker and } \\
\text { Cordray (1973) }\end{array}$ & 18 & Right & Laparotomy & $\begin{array}{c}\text { Contralateral } \\
\text { ovarian cyst }\end{array}$ \\
$\begin{array}{l}\text { Georgy and } \\
\text { Viechnicki (1974) }\end{array}$ & 45 & Left & Abdominal & Menorrhagia \\
Lashgari (1975) & 33 & Left & Laparoscopy & Sterilization \\
\hline
\end{tabular}

Features common to all three cases were:

(i) Absence of previous abdominal surgery.

(ii) Absence of history of significant acute abdominal pain.

(iii) Absence of uterine abnormalities.

(iv) Presence of the opposite appendage.

(v) Absence of obvious Müllerian duct abnormalities.

(vi) Presence of a normal renal tract.

explanation is that torsion occurred during fetal life. It has long been known that the abdominal testis is particularly liable to torsion (Scorer, 1962). Some cases of 'anorchia' and 'monorchia' have been attributed to testicular disappearance by torsion and infarction occurring during fetal life (Abeyratne, Aherne and Scott, 1969). A similar mechanism may well operate in the case of the ovary, with the distal uterine tube being involved in the process.

Furthermore, in the infarcted appendage it is almost impossible to ascertain its state before infarction. Although the authors of the first two cases state that torsion and infarction of normal adnexae had occurred, there is no evidence that the involved adnexae had in fact been normal. On the other hand, an abnormal adnexa such as that associated with an ovarian cyst is more liable to torsion than a normal uterine adnexa. There are many reports of ovarian cysts presenting in the neonatal period, both in full term and premature infants (Korobkin, De Loromier and Gooding, 1970; Graves, Mc Ilvoy and Hudson, 1951). It may be inferred that many of these were present during fetal life. Inasmuch as an adult ovarian cyst is liable to torsion, so would be a fetal ovarian cyst. For obvious reasons, torsion occurring in fetal life cannot be diagnosed and will only come to light later if laparotomy or laparoscopy is performed for some other reason. This may be the aetiology in all four reported cases.

In conclusion it may be said that torsion of a uterine adnexa after birth is always associated with acute abdominal symptoms and is a surgical emergency. There cannot be any such condition as 'asymptomatic' torsion and infarction. The incidental finding of an absent adnexa is probably the result of torsion and infarction of a normal or abnormal adnexa, occurring during fetal life.

\section{Acknowledgments}

I am indebted to my Consultant Mr E. G. Jonas, for the opportunity to manage a patient admitted under his care and $\mathrm{Mr} \mathrm{C}$. G. Scorer for helpful suggestions.

\section{References}

Abeyratne, M.R., Aherne, W.A. \& Scott, J.E.S. (1969) Vanishing testes. Lancet, ii, 822.

Georgy, F.M. \& ViechNicki, M.B. (1974) Absence of an ovary and uterine tube. Obstetrics and Gynecology, 44, 441.

GrosfelD, J.L. (1969) Torsion of normal ovary in the first two years of life. American Journal of Surgery, 117, 726.

Graves, G.Y., McIlvoy, D.B. \& Hudson, G.W. (1951) Ovarian cyst in a premature infant. American Journal of Diseases of Children, 81, 256.

JAmes, D.F., BARber, H.R.K. \& Graber, E.A. (1970) Torsion of normal uterine adnexa in children. Obstetrics and Gynecology, 35, 226.

Korobkin, M., De Loromier, A.A. \& Gooding, C.A. (1970) Ovarian cysts presenting in the neonatal period. British Journal of Radiology, 43, 820.

LASHgARI, M. (1975) Absence of ovary. Obstetrics and Gynecology, 46, 115.

SCORER, C.G. (1962) The anatomy of testicular descent normal and incomplete. British Journal of Surgery, 49, 357.

Sebastian, J.A., Baker, R.L. \& Cordray, D. (1973) Asymptomatic infarction of ovary and distal uterine tube. Obstetrics and Gynecology, 41, 531. 